\title{
Prototipe Pengaman Peralatan Instalasi Listrik dan Tegangan Sentuh Bagi Manusia dengan ELCB ( Earth Leakege Circuit Breaker )
}

\author{
Fr1ely Didit Sukardi ${ }^{1)}$, Abdul Zain ${ }^{2}$, Arief Muliawan ${ }^{3)}$ \\ ${ }^{1), 2,3)}$ Program Studi Teknik Elektro Sekolah Tinggi Teknologi Bontang (STITEK) Bontang, Indonesia \\ frely.didit87@gmail.com ${ }^{1)}$,jainbtg2013@gmail.com ${ }^{2}$, ariefstitek@gmail.com ${ }^{3)}$
}

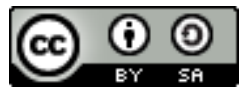

\begin{abstract}
Abstrak
Bahaya listrik merupakan ancaman yang tidak terlihat namun dapat menghilangkan nyawa manusia dan menyebabkan terjadinya kebakaran. Keselamatan faktor penting yang harus diterapkan dalam pemakaian tenaga listrik. Manusia hanya dapat merasakan sengatan listrik dengan maksimal arus yang melalui tubuh $30 \mathrm{~mA}$. Earth Leakage Circuit Breaker (ELCB) pada suatu sistem instalasi listrik merupakan salah satu solusi yang dapat digunakan untuk melindungi dari bahaya tegangan sentuh. Melakukan uji coba menggunakan sumber fasa dan netral sebagai media pengaktifan ELCB dan resistor sebagai pengganti tahanan tubuh manusia serta grounding sebagai media gangguan pentanahan. Dengan membandingkan arus masuk dan keluar pada fasa dan netral inilah sistem kerja ELCB. Waktu pemutusan tegangan dan arus listrik pada ELCB adalah $19.60 \mathrm{mS}$. Dengan Pengaplikasiaan ELCB dalam sistem instalasi listrik diharapkan bahaya yang diakibatkan oleh tegangan sentuh dapat dibatasi sehingga sistem aman bagi manusia.
\end{abstract}

Kata Kunci: Instalasi Listrik, Tegangan Sentuh, ELCB( Earth Leakage Circui Breaker ), Arus Bocor

\section{PENDAHULUAN}

Instalasi domestik adalah instalasi listrik dalam bangunan untuk perumahan/tempat tinggal, dan Instalasi non domestik adalah instalasi listrik bukan untuk perumahan atau industri misalnya, perkantoran, mal, pusat perbelanjaan dan lain-lain. Ruang lingkup instalasi terdiri atas Instalasi penerangan, instalasi PHB (Perlengkapan Hubung Bagi), gawai proteksi dan pembumian [1].

Keamanan merupakan suatu faktor pertimbangan yang ditempatkan pada urutan pertama dalam mendesain sebuah sistem instalasi listrik. Adanya ancaman bahaya bagi keselamatan manusia akibat arus bocor diatas ambang aman pada suatu sistem instalasi listrik merupakan suatu masalah yang harus dicarikan jalan keluarnya [2].

Beberapa kejadian kebakaran pada umumnya juga dikarenakan adanya hubung singkat listrik dari instalasi listrik yang kurang memperhatikan standar peralatan dan bangunan mestinya menjadi pelajaran penting dalam penyiapan sistem keselamatan. Pada saat terjadi kebakaran, ada empat hal yang perlu diperhatikan berkaitan dengan bahaya kebakaran, yaitu penghuni bangunan (manusia), isi bangunan (harta), struktur bangunan dan bangunan lainnya yang berada disebelah bangunan itu sendiri. Untuk menekan jumlah korban yang terus meningkat, perlu dilakukan suatu tindakan proteksi yang mengutamakan keselamatan. Peringatan dini terhadap arus bocor atau tanda-tanda kebakaran merupakan salah satu solusi dari menyelamatkan nyawa manusia. [3]

Pemilihan ELCB fasa satu dalam rangkaian pengujian didasarkan pada besarnya konsumen listrik rumah tangga yang hanya menggunakan sumber fasa satu. Tubuh manusia dalam rangkaian digantikan oleh suatu tahanan dengan nilai tertentu yang diambil dari hasil pengukuran tahanan tubuh manusia [4].

\section{KAJIAN LITERATUR}

\section{Persyaratan Umum Instalasi Listrik (PUIL) 2011}

Persyaratan Umum Instalasi Listrik 2011 merupakan hasil revisi dari PUIL 2000. PUIL ini sekarang telah diterbitkan dengan versi paling baru tahun 2011. BSN merilisnya dengan judul SNI 0225:2011 tentang PUIL 2011. Kemudian sudah dilakukan lagi amandemen 1 pada tahun 2013, sehingga judulnya sudah berubah menjadi SNI 0225:2011/Amd 1:2013. Pemerintah melalui 
Kementerian Energi Sumber Daya Manusia (ESDM), telah mengeluarkan Permen ESDM no. 36 tahun 2014 tentang pemberlakuan Standar Nasional Indonesia 0225:2011 mengenai persyaratan umum instalasi listrik 2011 (PUIL 2011) dan standar nasional Indonesia 0225:2011/Amd:2013 mengenai persyaratan umum instalasi listrik 2011 (PUIL 2011) amandemen 1 sebagai standar wajib. Peraturan ini ditandatangani oleh menteri Sudirman Said, pada tanggal 24 Desember 2014. Kemudian melalui siaran persnya no. 02/SJI/2015 pada tanggal 23 Januari 2015 yang ditandatangani oleh Saleh Abdurrahman, selaku kepala pusat komunikasi publik, menyiarkan bahwa SNI PUIL 2011 telah diberlakukan secara wajib

Sebagaimana Maksud dan tujuan Persyaratan Umum Instalasi Listrik ini ialah agar instalasi listrik dapat dioperasikan dengan baik, untuk menjamin keselamatan manusia, terjaminnya keamanan instalasi listrik beserta perlengkapannya, terjaminnya keamanan gedung serta isinya dari bahaya kebakaran, dan tercapainya tujuan dari pencahayaan yaitu terwujudnya interior yang efisien dan nyaman [5].

\section{MCB ( Miniature Circuit Breaker)}

Seperti halnya circuit breaker pada umumnya MCB berfungsi untuk untuk memutus jalannya arus gangguan yang terjadi pada peralatan agar kerusakan tidak menyebar keperalatan lain atau terjadi kerusakan yang lebih fatal lagi. Bedanya dengan sekering yang hanya dapat beroperasi sekali untuk memutus aliran arus kemudian harus diganti, sedangkan untuk miniature circuit breaker sendiri pemutus rangkaian dapat direset (baik secara manual atau secara otomatis) dapat melanjutkan operasi normal tanpa ada kerusakan pada circuit breaker tersebut.

\section{ELCB (Earth Leakage Circuit Breaker)}

Earth Leakege Circuit Breaker (ELCB) adalah pemutus yang peka terhadap arus bocor, yang dapat memutuskan sirkit termasuk penghantar netralnya secara otomatis dalam waktu tertentu. Alat ini dipergunakan sebagai pengaman bila terjadi arus bocor pada salah satu penghantar yang melalui alat tersebut. Prinsip kerja ELCB sistem fasa tunggal ditunjukkan pada Gambar 1. Bila tidak ada arus bocor (ke tanah atau tubuh manusia) maka jumlah arus yang mengalir dalam kedua penghantar ( $\mathrm{N}$ dan L1) sama dengan nol. Sehingga trafo arus (CT) tidak mengalami induksi dan trigger elektromagnet tidak aktif. Namun sebaliknya bila ada arus bocor, maka jumlah resultan arus tidak sama dengan nol, CT menginduksikan tegangan dan mengaktifkan trigger sehingga alat pemutus daya ini bekerja memutuskan beban dari sumber [6].

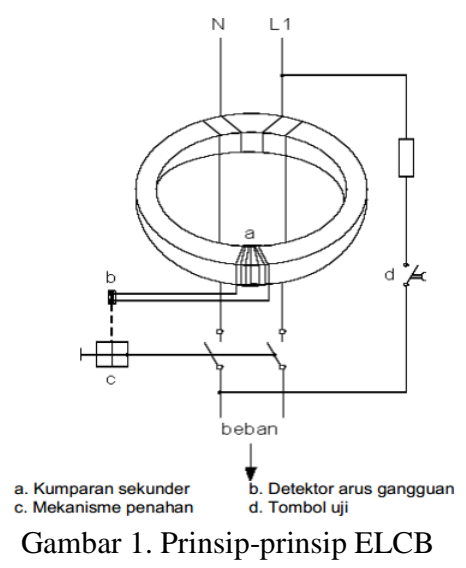

Dalam keadaan normal, jumlah arus yang dilingkari oleh inti transformator sama dengan nol. Apabila ada arus bocor ke tanah, keadaan seimbang akan terganggu. Karena itu dalam inti transformator timbul suatu medan magnetik yang membangkitkan tegangan dalam kumparan sekunder. Apabila arus bocor tersebut mencapai pada suatu harga tertentu maka relay pada ELCB bekerja melepaskan kontak-kontaknya.

\section{METODE PENELITIAN}

\section{Sistem Instalasi Kelistrikan}

Sebelum mengenal jauh tentang simulasi ini, maka sebaiknya harus mengetahui bagaimana rangkaian sebuah instalasi rumah tinggal yang dapat membantu untuk memudahkan dalam pemasangan dan efisiensi terhadap penggunaan listrik rumah tangga. Salah satu cara tersebut adalah dengan merangkai sebuah instalasi rumah tinggal dengan menggunakan rangkaian seri dan paralel, yang mana dengan merangkai rangkaian seri akan dapat membuat arus pada rangkaian tersebut tetap konstan jika memiliki beban dengan kapasitas yang sama. Juga merangkai rangkaian paralel dengan bertujuan untuk membagi tegangan agar bisa membuat percabangan terhadap kebutuhan sumber power 
terhadap beban. Namun, sebelum itu juga harus mengetahui bagaimana overall tentang sistem diagram kelistrikan dari simulasi instalasi ini. Berikut adalah gambar simulasi diagram kelistrikan instalasi rumah menggunakan ELCB.

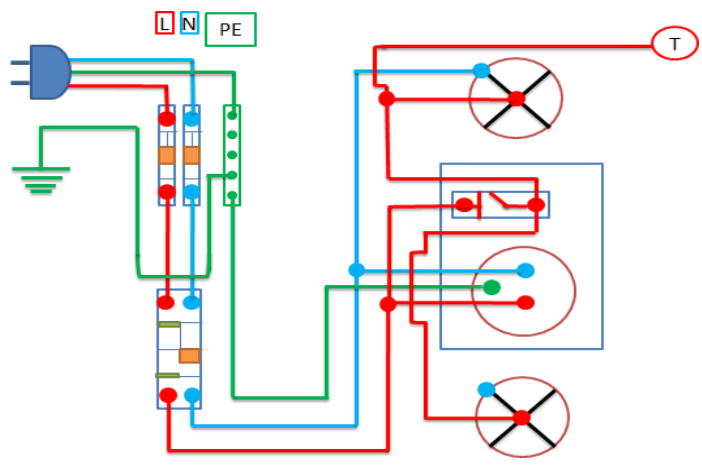

Gambar 2. Rangkaian Pengawatan Instalasi Rumah

\section{Tegangan Sentuh}

Tegangan sentuh adalah [5] tegangan yang terdapat diantara suatu objek yang disentuh dan suatu titik berjarak 1 meter, dengan asumsi bahwa objek yang disentuh dihubungkan dengan kisi-kisi pentanahan yang berada dibawahnya, seperti pada gambar 3 di bawah ini.

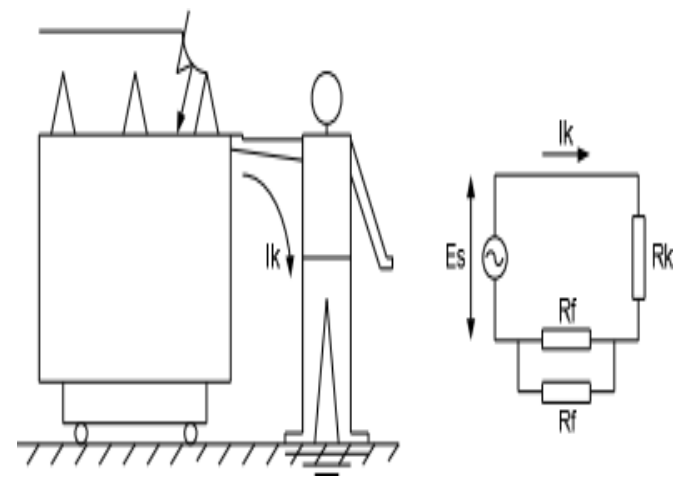

Gambar 3. Tegangan sentuh dan rangkaian ekivalennya

Dari rangkaian ekivalen didapat persamaan tegangan sentuh,yaitu :

$$
E_{s}=\left(R_{k}+\frac{R_{f}}{2}\right) \cdot I_{k}
$$

Dimana :

$\mathrm{E}_{\mathrm{S}}=$ Tegangan sentuh $(\mathrm{V})$

$\mathrm{Rk}=$ Tahanan badan manusia $(\Omega)$

$\mathrm{Rf}=$ Tahanan kontak ke tanah dari satu

kaki pada tanah $(\Omega)$

$\mathrm{Ik}=$ Arus yang melalui tubuh (A)
Tegangan sentuh yang terlalu tinggi harus diberikan proteksi agar tidak membahayakan. Prinsip Fundamental dijelaskan dalam Bagian 1 dan Bagian 2 PUIL 2011. Prinsip fundamental 131 (2.1) Proteksi untuk keselamatan $131.2 \quad$ (2.1.2) Proteksi terhadap kejut listrik $131.1 \quad$ (2.1.1) Umum 131.2.1 (2.1.2.1) Proteksi dasar (proteksi terhadap sentuh langsung) (2.1.1.1) Persyaratan yang dinyatakan dalam 131.2 hingga 131.7 dimaksudkan untuk memastikan keselamatan manusia dan ternak serta keamanan harta benda dari bahaya dan kerusakan yang dapat timbul oleh penggunaan instalasi listrik secara wajar. Persyaratan untuk memastikan keselamatan ternak dapat diterapkan pada lokasi yang dimaksudkan untuk kandang ternak. Proteksi harus disediakan terhadap bahaya yang dapat timbul karena sentuh dengan bagian aktif instalasi oleh manusia atau ternak. Pada instalasi listrik bahaya berikut dapat timbul, yaitu: a) arus kejut listrik; b) suhu berlebihan yang mungkin mengakibatkan kebakaran, luka bakar atau efek cedera lain; c) penyulutan atmosfer ledak yang potensial; d) voltase kurang, voltase lebih dan pengaruh elektromagnetik yang mungkin menyebabkan cedera atau kerusakan; e) pemutusan suplai daya dan/atau pemutusan pelayanan keselamatan; f) busur api listrik, yang mungkin menyebabkan efek menyilaukan, tekanan yang berlebihan atau gas racun; g) gerakan mekanis perlengkapan yang digerakkan listrik. Untuk instalasi voltase rendah, sistem dan perlengkapan, proteksi dasar umumnya berkaitan dengan proteksi terhadap sentuh langsung.

\section{Faktor Penentu Keseriusan Akibat Sengatan Listrik}

Ada tiga faktor yang menentukan keseriusan sengatan listrik pada tubuh manusia, yaitu [7] :

a Besar arus listrik yang mengalir dalam tubuh ditentukan oleh tegangan dan tahanan tubuh. Tegangan tergantung pada sistem tegangan yang digunakan, sedangkan tahanan tubuh manusia bervariasi tergantung pada jenis, kelembaban kulit dan faktor-faktor lain seperti ukuran tubuh dan berat badan. Tahanan kontak kulit bervariasi dari $1000 \mathrm{k} \Omega$ (kulit kering) sampai $100 \Omega$ (kulit basah). Tahanan dalam (internal) tubuh sendiri antara 100-500 $\Omega$ [8]. 
b. Lintasan arus listrik dalam tubuh juga sangat menentukan tingkat akibat sengatan listrik. Lintasan yang sangat berbahaya adalah yang melewati jantung, dan pusat saraf (otak).

c. Lama waktu sengatan listrik ternyata sangat menentukan kefatalan akibat sengatan listrik. Penemuan faktor ini menjadi petunjuk yang sangat berharga bagi pengembangan teknologi proteksi dan keselamatan listrik. Semakin lama waktu tubuh dalam sengatan semakinfatal pengaruh yang diakibatkannya.

Oleh karena itu, yang menjadi ekspektasi dalam pengembangan teknologi adalah bagaimana bisa membatasi sengatan agar dalam waktu sependek mungkin, menunjukkan bagaimana pengaruh sengatan listrik terhadap tubuh, khususnya yang terkait dengan dua faktor, yaitu besar dan lama arus listrik mengalir dalam tubuh [9].

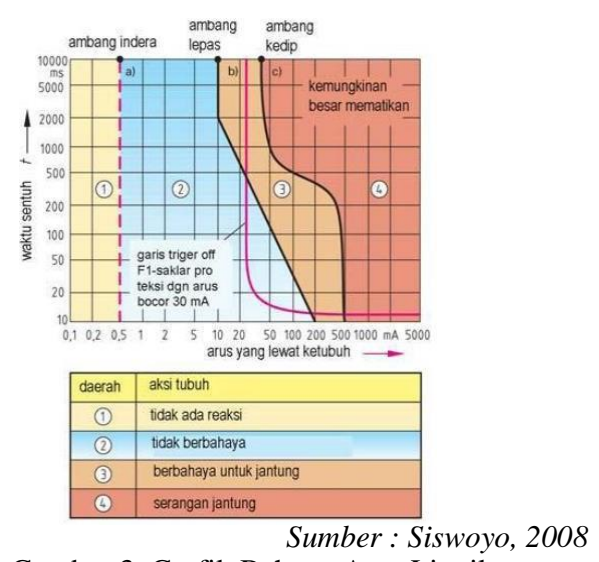

Gambar 3. Grafik Bahaya Arus Listrik

\section{Perancangan Sistem}

Dalam hal ini penulis merancang sebuah simulasi instalasi listrik rumah tinggal yang mengunakan ELCB dapat dilihat pada gambar 4 sebagai pengaman tegangan sentuh secara langsung pada peralatan dan pada tubuh manusia secara sederhana yang mana dibuat seaman mungkin dalam proses simulasi berlangsung. Juga, menambahkan grounding atau pentanahan sebagai bagian media pembuangan arus bocor kebumi atau tanah.

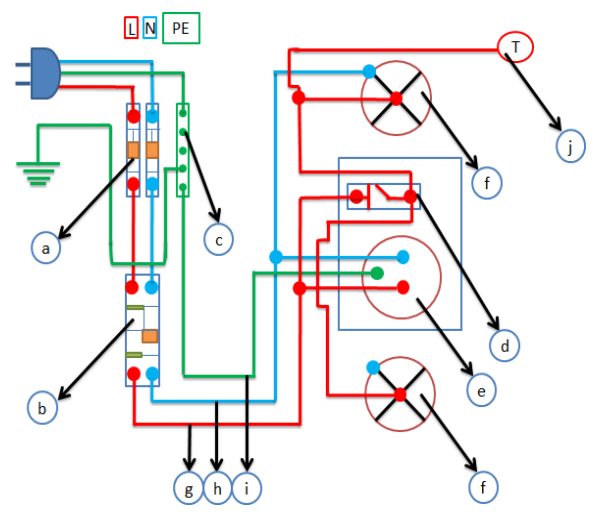

Gambar 4. Simulasi Pengawatan Instalasi Rumah Prototipe ELCB

Keterangan Simbol :

a. MCB.

b. ELCB.

c. Terminal PE (Pentanahan).

d. Saklar.

e. Stop Kontak.

f. Fitting dan Lampu.

g. Kabel fasa (L).

h. Kabel Netral (N).

i. Kabel Ground (PE).

j. Kabel pengetesan simulasi arus bocor.

\section{HASIL DAN PEMBAHASAN}

Hasil Instalasi Listrik Menggunakan ELCB

Setelah proses perancangan dan perakitan dari semua komponen-komponen dan peralatan-peralatan untuk simulasi intalasi rumah menggunakan ELCB, alatpun sudah siap untuk dilakukan ujicoba dan pengambilan data untuk proses tugas akhir ini. Setelah itu dilakukan ujicoba dengan mengaktifkan dari keseluruhan alat dalam keadaan normal. Hasil rancangan dan perakitan dituangkan dalam Gambar 5.

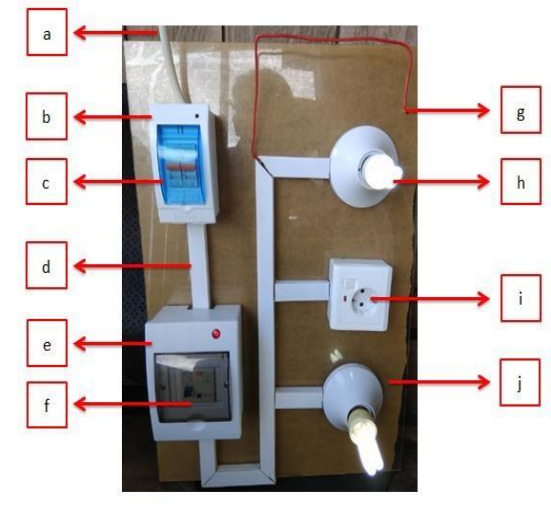

Gambar 5. Perancangan Simulasi Instalasi Listrik Dengan ELCB 
Keterangan :

a. Kabel Power 3x2.5 mm NYFA.

b. Box MCB.

c. MCB 2 x4A.

d. Kabel Reel.

e. Box ELCB.

f. ELCB $1 \mathrm{P}+\mathrm{N}$ 6A Sensitivitas 30mA.

g. Kabel Simulasi Arus Bocor.

h. Fitting dan Lampu.

i. Stop Kontak dan Saklar 2 Titik. Papan Mika A2.

\section{Hasil Simulasi Beberapa Faktor Penyebab ELCB Bekerja.}

Setelah hasil perancangan dan perakitan telah dicoba atau ditest dalam keadaan normal hasilnya baik dan juga normal, maka akan dilakukan beberapa cara atau metode yang dapat mengaktifkan dari sistem kerja ELCB. Metode tersebuat akan dituangkan dalam beberapa cara berikut :

\section{Hasil Percobaan Kabel Fasa Lampu}

Sebagai Arus Bocor dan Resistor Pengganti Tahanan Tubuh Manusia

Metode ini dimaksudkan dengan sebagaimana buruknya instalasi luar rumah atau outdoor, yang mana dikarenakan jeleknya suatu instalasi tersebut terjadilah sebuah kabel fasa yang mengalami kerusakan namun masih bertegangan dan mengenai bagian tubuh manusia dan digantikan oleh sebuah resistor $5100 \Omega$. Karena tahanan tubuh manusia pada saat kering yang paling dominan tahanan tubuhnya adalah $5000 \Omega$. Dimana kabel ground atau pentanahan tersebut disimulasikan seperti pada gambar 6 sebagai tanah atau bumi yang telah diinjak oleh manusia tersebut setelah itu terjadi perbedaan pembacaan arus yang menyebabkan ELCB trip dalam waktu 19.60 $\mathrm{mS}$ seperti terlihat pada gambar 7 .

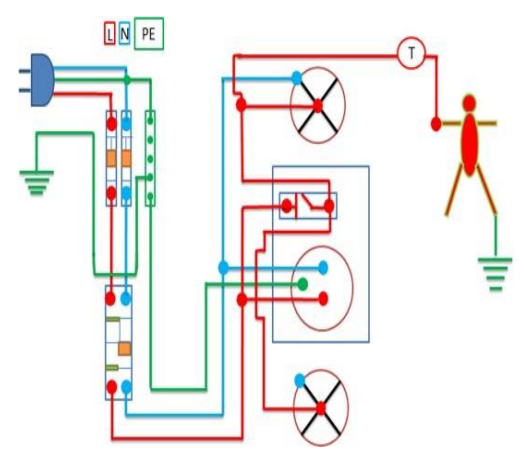

Gambar 6. Pengawatan Arus Bocor Pada Fasa (L-PE)

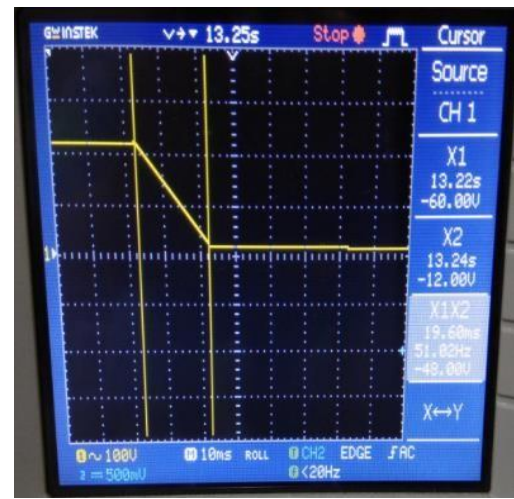

Gambar 7. Hasil Waktu Triping ELCB

2. Hasil Percobaan Kabel Netral Beban Lampu Sebagai Arus Bocor dan Resistor Pengganti Tahanan Tubuh Manusia.

Metode ini dimaksudkan dengan sebagaimana buruknya instalasi luar rumah atau outdoor, yang mana dikarenakan jeleknya suatu instalasi tersebut terjadilah sebuah kabel netral yang mengalami kerusakan namun masih bertegangan dan mengenai bagian tubuh manusia dan digantikan oleh sebuah resistor $5100 \Omega$. Karena tahanan tubuh manusia pada saat kering yang paling dominan tahanan tubuhnya adalah $5000 \Omega$. Dimana kabel ground atau pentanahan tersebut disimulasikan sebagai tanah atau bumi yang telah diinjak oleh manusia seperti pada gambar 8 dan ternyata ELCB tidak trip karena tidak mendeteksi terjadinya gangguan arus yang melewati resistor dan kawat pentanahan.

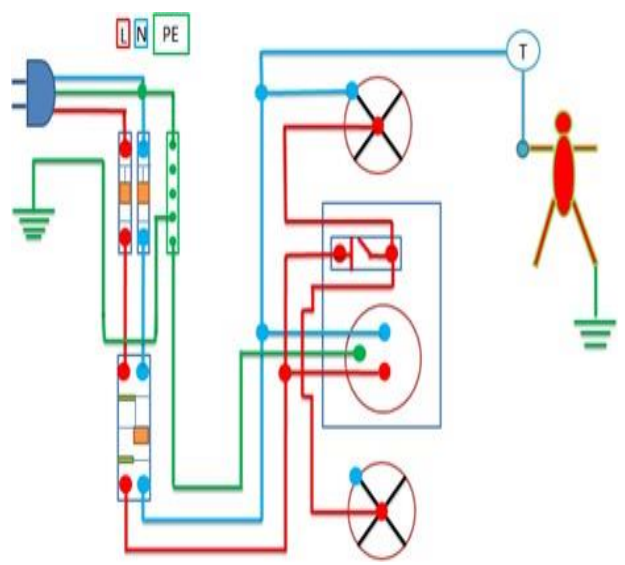

Gambar 8. Pengawatan Arus Bocor Netral $(\mathrm{N}-\mathrm{PE})$ 
3. Hasil Percobaan Kabel Fasa Lampu Sebagai Arus Bocor Yang Terkena Oleh Beban Lain Yang Terpasang Grounding/Pentanahan.

Kabel fasa output beban dari ELCB mengalami kerusakan isolasi tersentuh dengan bodi yang terbuat dari konduktor yang merupakan beban lain dan sudah terhubung dengan pentanahan yang masih dalam keadaan beroperasi, apakah dapat mengaktifkan fungsi kerja dari ELCB tersebut.? Jawabannya adalah bisa mengaktifkan fungsi kerja dari ELCB tersebut. Dalam hal ini dituangkan dalam gambar 9 ujicoba yang dianalogikan suatu instalasi rumah tangga tersebut merupakan instalasi yang sangat buruk.

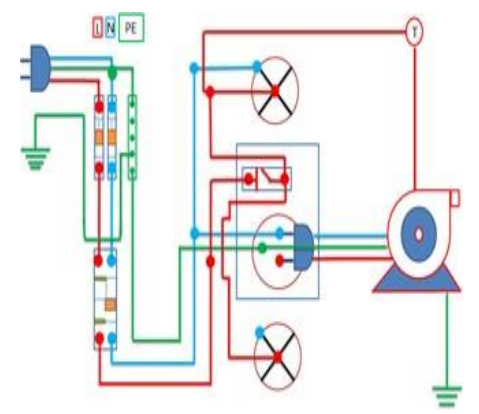

Gambar 9. Pengawatan Arus Bocor (L-PE)

\section{Hasil Pengujian Waktu Tripping Data Sheet dan Real Tripping}

Pengujian terhadap seberapa cepatnya waktu $(\Delta \mathrm{t})$ tripping atau pemutusan ELCB pada saat terjadi gangguan arus bocor atau pun gangguan pentanahan dan lainlainnya. Penulis mencoba membandingkan waktu pemutusan yang ada pada data sheet ELCB dengan real pemutusan yang terjadi pada saat gangguan arus bocor dan sebagainya

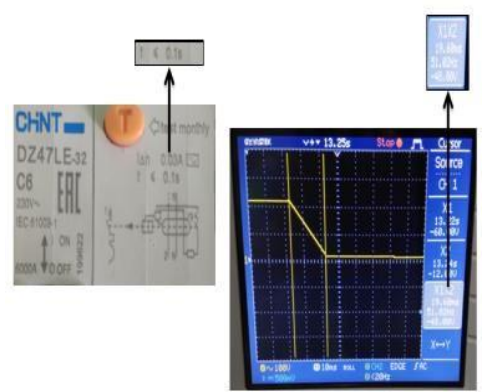

seperti pada gambar 10 .

Gambar 10. Hasil Perbandingan Waktu Tripping ELCB
Jadi, dapat diketahui bahwa waktu tripping $(\Delta \mathrm{t})$ pada data sheet yang ada pada ELCB adalah $\mathrm{t} \leq 0.1 \mathrm{~s}$. Pada hasil percobaan yang telah dilakukan telah didapatkan hasil tripping pada waktu real yang terjadi pada ELCB adalah $19.60 \mathrm{~ms}=0.0196 \mathrm{~s}$. Dapat ditarik kesimpulan bahwa alat ini bekerja lebih cepat dalam waktu pemutusan lebih cepat dari waktu yang ada pada data sheet.

\section{Hasil Percobaan Maksimum Tahanan Terhadap Sistem Kerja ELCB}

Pada data sheet sebelumnya tidak ada spesifikasi dari ELCB yang menunjukkan bahwa adanya maksimum gangguan tahanan yang dapat menyebabkan ELCB dapat bekerja. Pada percobaan ini telah dilakukan pengujian terhadap batas maksimal kerja triping pada ELCB. Hal ini digunakan resistor sebagai penganti tahanan tubuh manusia. Dalam metode pengaktifan ELCB telah ditambahkan beberapa tahahan untuk mengetahui seberapa cepat dan seberapa maksimal ELCB bekerja seperti terlihat pada tabel 1 .

Tabel 1. Data Penelitian Maksimum Pemutusan ELCB

\begin{tabular}{ccc}
\hline $\begin{array}{c}\text { Metode Uji } \\
\text { Coba }\end{array}$ & Resistor & Waktu Trip \\
\hline L-PE & $5100 \Omega$ & $19.60 \mathrm{mS}$ \\
L-PE & $10200 \Omega$ & $19.60 \mathrm{mS}$ \\
L-PE & $10700 \Omega$ & $19.60 \mathrm{mS}$ \\
L-PE & $10800 \Omega$ & Tidak Trip \\
L-PE & $17300 \Omega$ & Tidak Trip \\
\hline
\end{tabular}

\section{KESIMPULAN}

Berdasarkan hasil penelitian yang telah dilakukan oleh penulis dapat diambil kesimpulan bahwa :

1. ELCB (Earth Leakage Circuit Breaker) dapat mencegah sengatan langsung yang disebabkan oleh kebocoran arus yang disebabkan oleh kegagalan isolasi kabel yang mana harus ditambahkan sistem pentanahan didalam penggunaan alat tersebut.

2. ELCB dapat bekerja dengan baik dan efektif yakni dengan membaca akan adanya perbedaan arus yang masuk dan keluar antara fasa dan netral yang mana dengan sensitivitas $30 \mathrm{~mA}$ akan memutuskan sumber tegangan yang ada pada output ELCB dengan $19.60 \mathrm{~ms}$. 
Saran untuk pengembangan penelitian ini yaitu alat ini diset pada sensitivitas $30 \mathrm{~mA}$ merupakan settingan yang menjadi ambang batas manusia dalam menerima tahanan dan arus listrik. Akan lebih baik jika kedepannya akan ada percobaan dengan sensitivitas yang lebih kecil dibandingkan yang telah ada sekarang. Serta, menggunakan oscilloscope yang memiliki versi paling baru dari yang sekarang untuk memperjelas dalam percobaan waktu tripping ELCB.

\section{UCAPAN TERIMA KASIH}

Penulis menyampaikan terima kasih kepada seluruh pihak yang telah memberikan kontribusi yang positif bagi penyelesaian penelitian ini yakni :

1. Ketua Prodi Teknik Elektro Stitek Bontang

2. Ketua LPPM Stitek Bontang

3. Dosen dan Staf Stitek Bontang

\section{REFERENSI}

[1]

S. Heru, Sulaeman. "Materi Sertifikasi Pelatihan Keahlian Teknik Listrik". Asosiasi Profesionalis Elektrikal Indonesia ( APEI), 2009.

[2] Nugroho, Rohmat, "Studi Arus Bocor dengan metode pengkuran Inclined Plane Tra'cking (IPT) pada material polimer High Density Polyethylene (HDPE),"” 2009.

[3] Abdul Zain, Rancang Bangun Sistem Proteksi kebakaran menggunakan Smoke and heat detector. INTEK, 2016. Vol.3 (1), 36-42.

[4] Sarunggalo, Pandung, "Perancangan Earth Leakage Circuit Breaker dengan Sensitivitas $20 \mathrm{~mA}$ ". Universitas Negeri Papua. 2008.

[5] BSN, "Persyaratan Umum Instalasi Listrik 2011 (PUIL 2011)," SNI 0225:2011/Amd 1:2013.

[6] Harten, P.Van, Setiawan, Ir.E. "Instalasi Listrik Arus Kuat I. Binacipta Bandung, 1980.

[7] Sumardjati, Prih. "Teknik Pemanfaatan Listrik 1. Direktorat Pembinaan SMK," 2008.
[8] T.S. Hutahuruk. "Pengetanahan Netral Sistem Tenaga dan Pengetanahan Peralatan. Erlangga. 1991.

[9] Siswoyo. "Teknik Listrik Industri III. Direktorat Pembinaan SMK," 2008.

[10] Daniel K, M Nurdin, Syahrir, Zainal A,2017, Pengembangan Soft Starting Dengan Kontrol PID Pada Motor Induksi Berbasis Mikrokontroller, Jurnal Teknologi Elekterika, Vol 14, No 2. ISSN 1412-8764 